\title{
Mixed-lymphocyte reaction as a measure of immunological competence of lymphocytes from patients with Crohn's disease
}

\author{
ElizABETH R. Richens, M. J. Williams, K. R. GOUGH, AND R. J. ANCILL \\ From the Pharmacology Department, University of Bath, and Department of Clinical Investigation, \\ Royal United Hospital, Bath
}

SUMMARY Peripheral blood lymphocytes from 12 patients with Crohn's disease and from a group of normal volunteers have been tested for transformation under stimulation of allogeneic cells in a mixed lymphocyte culture and by phytohaemagglutinin (PHA) in vitro. There was a significant depression of transformation in the mixed lymphocyte culture where lymphocytes from the Crohn's disease patients constituted the responding population. With PHA stimulation, no difference in transformation was seen between the patients and the control group. This is interpreted as indicating a depression in cellular immunity in Crohn's disease.

A generalized depression of delayed hypersensitivity reactions has been noted in Crohn's disease. It is illustrated by such features as an impaired skin response to dinitrochlorobenzene (Jones, Housley, Ashurst, and Hawkins, 1969) and the tendency of Crohn's patients to be tuberculin negative (Williams, 1965). However, natural antigens elicit a normal response (Brown, Taub, Present, and Janowitz, 1970).

Further suggestions of anergy are given by the reduced transformation of lymphocytes in vitro under the stimulus of PHA (Walker and Greaves, 1969) and the failure to produce a macrophage inhibition factor in the presence of tissue antigens (Bendixen and Søberg, 1969).

In this communication, we report further investigations of immunocompetence of Crohn's patients using the technique of lymphocytic blastogenesis by stimulation with allogeneic cells in the mixed lymphocyte reaction and with PHA.

\section{Materials and Methods}

PATIENTS AND CONTROL SUBJECTS

Twelve patients with Crohn's disease, proven by radiological or histological evidence, were studied. Age, sex, duration of disease, and immunosuppressive treatment are shown in table II. Activity of

Received for publication 26 October 1973. disease was judged on clinical criteria, including fever, weight loss, abdominal pain, and diarrhoea.

Twenty-one healthy controls were studied concurrently. For the PHA studies patients and controls were matched as far as possible for age and sex. HL-A phenotypes of the controls and patients were determined by the National Tissue Typing Reference Laboratory, Southmead. These data are listed in tables I and II.

PREPARATION OF CELLS

Cells for both tests were prepared from $50 \mathrm{ml}$ freshly

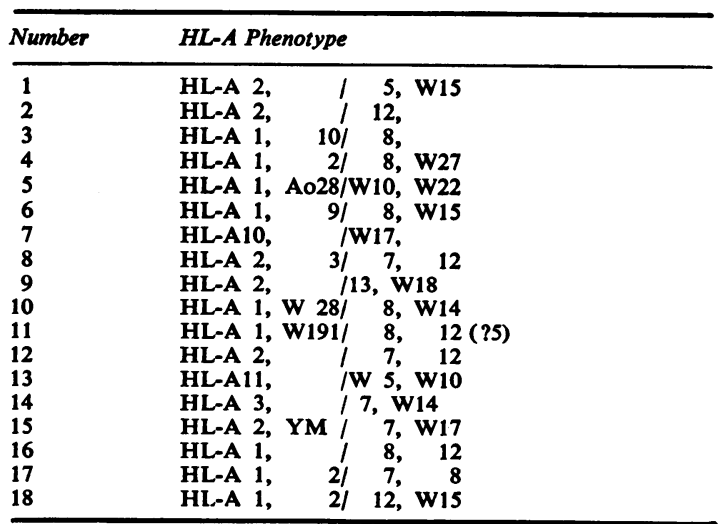

Table I HL-A phenotypes of normal control patients 


\begin{tabular}{|c|c|c|c|c|c|c|}
\hline Number & HL-A Phenotype & Age & $\operatorname{Sex}$ & $\begin{array}{l}\text { Duration in } \\
\text { Years }\end{array}$ & Activity & Immunosuppression \\
\hline $\begin{array}{l}19 \\
20 \\
21 \\
22 \\
23 \\
24 \\
25 \\
26 \\
27 \\
28 \\
29 \\
30\end{array}$ & 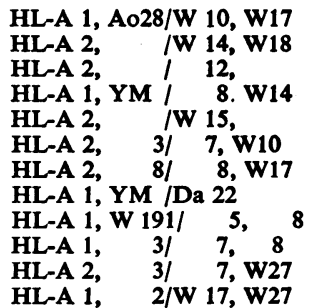 & $\begin{array}{l}23 \\
47 \\
29 \\
34 \\
55 \\
28 \\
28 \\
55 \\
26 \\
20 \\
17 \\
66\end{array}$ & $\begin{array}{l}\mathbf{F} \\
\mathbf{M} \\
\mathbf{F} \\
\mathbf{F} \\
\mathbf{F} \\
\mathbf{F} \\
\mathbf{M} \\
\mathbf{F} \\
\mathbf{F} \\
\mathbf{M} \\
\mathbf{M} \\
\mathbf{F}\end{array}$ & $\begin{array}{r}5 \\
3 \\
1 \\
16 \\
8 \\
13 \\
6 \\
9 \\
2 \\
4 \\
1 \\
20\end{array}$ & $\begin{array}{l}+ \\
+ \\
+ \\
+ \\
+ \\
+ \\
+ \\
+ \\
+ \\
+ \\
+ \\
+\end{array}$ & $\begin{array}{l}- \\
- \\
- \\
\text { Prednisone } \\
\text { Azathioprine } \\
\text { Prednisone } \\
\text { - } \\
\text { Azathioprine } \\
\text { - } \\
\text { - }\end{array}$ \\
\hline
\end{tabular}

Table II $H L-A$ phenotypes and clinical details of Crohn's patients.

taken heparinized blood (20 iu preservative-free heparin per $\mathrm{ml}$ whole blood). The blood was layered over a mixture of Ficoll (6.5\%) and Triosil $(11.7 \%)$ and centrifuged at $1000 \mathrm{~g}$ for 25 minutes at $20^{\circ} \mathrm{C}$. The lymphocyte band was removed and

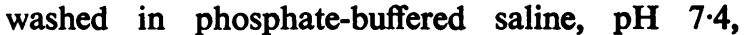
before being suspended in tissue culture medium (see below) to a concentration of $10^{6}$ cells per $\mathrm{ml}$. Cells for mixed lymphocyte reactions were divided into two aliquots, one of which was given 4000r irradiation in a ${ }^{60} \mathrm{Co}$ source.

\section{CULTURE CONDITIONS}

Cells were cultured at $37^{\circ} \mathrm{C}$ in a humidified incubator in a medium consisting of TC 199 with Earle's salts buffered with $20 \mathrm{~m}$ M Hepes, supplemented with penicillin (100 U per $\mathrm{ml})$, streptomycin (100 U per $\mathrm{ml}), 20 \%$ autologous plasma, and $2 \mathrm{mM} \mathrm{L}$ glutamine. Each cell suspension was made up in this medium before mixing for the mixed lymphocyte culture reaction.

For the mixed lymphocyte culture experiments $1 \times 10^{6}$ lymphocytes in culture medium from the responding population were mixed with an equal number of lymphocytes from the irradiated stimulating population of allogeneic cells. The control consisted of responding cells mixed in equal numbers with stimulating cells from the same individual. In any series of experiments mixed lymphocyte cultures were performed using two control subjects and one Crohn's patient, each set of cells being used both as stimulators and responders with all cell types available.

Lymphocytes from each individual were also cultured in the presence of 1:20 PHA (PHA-m, Difco). This concentration was found to be optimal in experiments with two healthy subjects (table III). The control cultures for these cells consisted of irradiated cells cultured with PHA.

All determinations were made using triplicate cultures.

\begin{tabular}{lll}
\hline PHA Concentration & Subject A & Subject $B$ \\
\hline $1: 10$ & 16.9 & 26.7 \\
$1: 20$ & 20.2 & 51.0 \\
$1: 40$ & $9 \cdot 1$ & 34.6 \\
$1: 80$ & 10.6 & 14.9 \\
$1: 160$ & 4.2 & 5.6 \\
\hline
\end{tabular}

Table III Transformation indices obtained at varying concentrations of PHA in two healthy subjects

\section{LABELLING AND HARVESTING CULTURES}

Using predetermined kinetic data, a four-hour radioactive pulse was given on the third day for the PHA cultures and on the seventh day for mixed lymphocyte cultures. This consisted of $1.0 \mathrm{u} \mathrm{Ci}$ thymidine-(methyl-H3) $(5 \cdot 0 \mathrm{Ci} / \mathrm{mmol}$, Amersham).

Cultures were terminated by cooling to $0^{\circ} \mathrm{C}$ and harvested onto glass fibre filter pads (GF/C, Whatman). Material remaining in the culture tube was washed onto the pad with $40 \mathrm{ml}$ ice-cold saline and acid-insoluble material precipitated with $20 \mathrm{ml}$ ice-cold 5\% trichloracetic acid. The filter pads were finally washed with $20 \mathrm{ml}$ methanol, placed precipitate side up in scintillation vials, and dried at $120^{\circ} \mathrm{C}$ for four hours. Ten $\mathrm{ml}$ scintillation fluid $(0.4 \%$ PPO, $0.005 \%$ POPOP in toluene) was added and the samples were counted in a Phillips scintillation counter, corrected for quench.

\section{Results}

The results for the mixed lymphocyte culture experiments were expressed in terms of a transformation index calculated as the ratio of radioactive thymidine incorporated in the allogeneic culture to its incorporation in a control culture consisting of the responding subjects' own cells as stimulators. Transformation indices obtained by this method are shown in figure 1.

The results for the PHA experiments were expressed as a transformation index calculated as the 


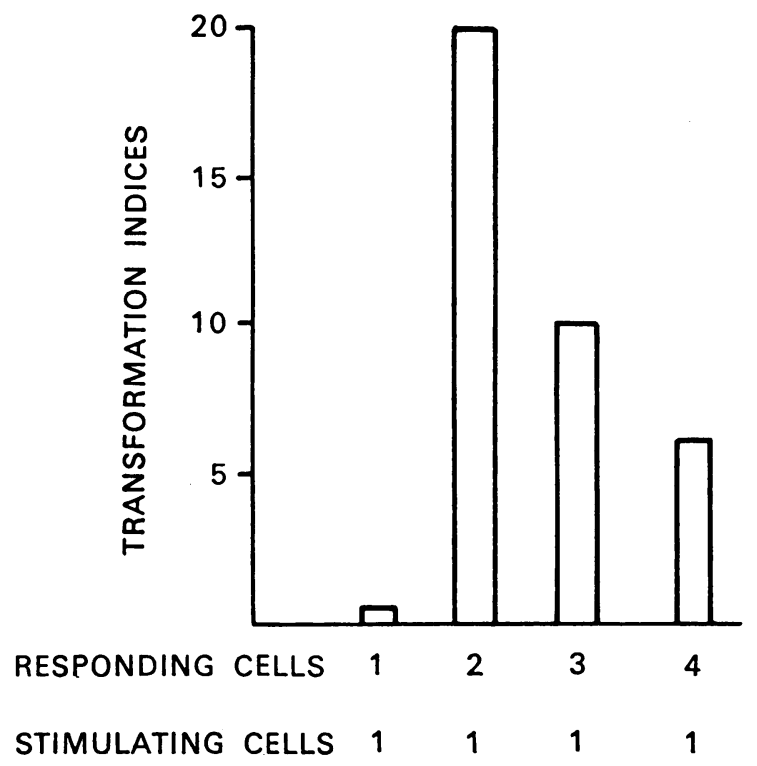

Fig 1 Transformation indices obtained in the mixed lymphocyte reaction using lymphocytes from subject $I$ as stimulating population and lymphocytes from various subjects as responding population. ratio of radioactive thymidine incorporated in non-irradiated to irradiated cells.

Figure 2 summarizes the transformation indices obtained for mixed lymphocyte cultures using lymphocytes from patients and control subjects as both stimulating and responding populations. It shows the following features:

1 When both stimulating and responding cells came from the control group a range of transformation indices from $2 \cdot 1$ to 580.0 was obtained.

2 When the responding cells came from the Crohn's patient group and the stimulating cells from the control subject group the range of transformation indices was $2 \cdot 1$ to $33 \cdot 8$.

3 When the responding cells came from the control subject group and the stimulating cells from the Crohn's patient group the range of transformation indices was $2 \cdot 1$ to $310 \cdot 0$.

Using the Mann-Whitney two-sample ranking test, it is seen that in the group where Crohn's patient lymphocytes are the responding population the results are significantly different from both the other groups at the $5 \%$ level. This suggests a degree of anergy in the Crohn's patients.

The transformation indices were not found to

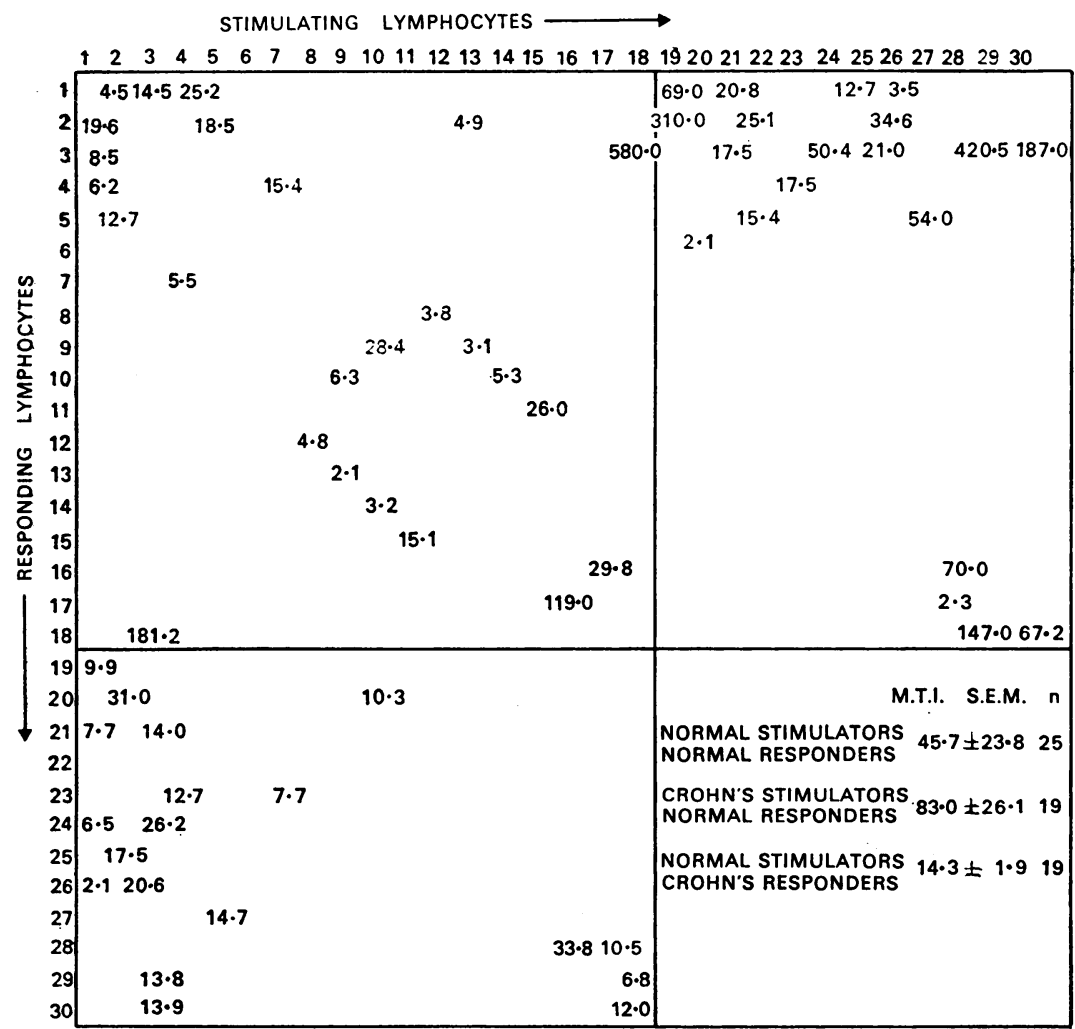

Fig 2 Summary of transformation indices obtained in the mixed lymphocyte reaction using lymphocytes from normal subjects (1-18) and Crohn's patients (19-30) both as the responding and stimulating populations. 


\begin{tabular}{|c|c|c|c|c|c|c|c|}
\hline \multicolumn{4}{|c|}{ Crohn's Patients } & \multicolumn{4}{|c|}{ Normal Controls } \\
\hline No. & $\operatorname{Sex}$ & Age & $\begin{array}{l}\text { Transformation } \\
\text { Index }\end{array}$ & No. & $\operatorname{Sex}$ & Age & $\begin{array}{l}\text { Transformation } \\
\text { Index }\end{array}$ \\
\hline $\begin{array}{l}21 \\
22 \\
23 \\
24 \\
25 \\
26 \\
27 \\
28 \\
29 \\
30\end{array}$ & $\begin{array}{l}\mathbf{F} \\
\mathbf{F} \\
\mathbf{F} \\
\mathbf{F} \\
\mathbf{M} \\
\mathbf{F} \\
\mathbf{F} \\
\mathbf{M} \\
\mathbf{M} \\
\mathbf{F}\end{array}$ & $\begin{array}{l}29 \\
34 \\
55 \\
28 \\
28 \\
55 \\
26 \\
20 \\
17 \\
66\end{array}$ & $\begin{array}{r}10 \cdot 2 \\
29 \cdot 1 \\
2 \cdot 2 \\
9 \cdot 0 \\
5 \cdot 6 \\
4 \cdot 1 \\
5 \cdot 7 \\
24 \cdot 6 \\
2 \cdot 6 \\
17 \cdot 0\end{array}$ & $\begin{array}{r}16 \\
2 \\
31 \\
7 \\
3 \\
18 \\
4 \\
5 \\
32 \\
33\end{array}$ & $\begin{array}{l}\mathbf{F} \\
\mathbf{F} \\
\mathbf{F} \\
\mathbf{F} \\
\mathbf{M} \\
\mathbf{F} \\
\mathbf{F} \\
\mathbf{M} \\
\mathbf{M} \\
\mathbf{F}\end{array}$ & $\begin{array}{l}29 \\
30 \\
57 \\
28 \\
29 \\
51 \\
24 \\
24 \\
16 \\
70\end{array}$ & $\begin{array}{r}17.6 \\
4.4 \\
3.8 \\
6.1 \\
15.5 \\
2.4 \\
26.4 \\
4.4 \\
16.0 \\
9.2\end{array}$ \\
\hline \multicolumn{4}{|c|}{ Mean $T I=11.4$} & \multicolumn{4}{|c|}{ Mean $T I=10.8$} \\
\hline
\end{tabular}

Table IV Transformation indices (TI) obtained on stimulation of lymphocytes by PHA

correlate with either calculated or possible incompatibilities in HL-A phenotypic antigens.

Table IV shows the transformation indices for both the normal subjects and the Crohn's patients after stimulation by PHA. The two groups have the same mean transformation index and are not significantly different by either the Mann-Whitney $\mathrm{U}$ test or the $\mathrm{t}$ test. Hence by this method of stimulation the Crohn's patients show no difference in response from the normal subjects.

Table V summarizes the mean counts $( \pm$ SEM) obtained for each of the groups of patients and control subjects in both the mixed lymphocyte culture and PHA series of experiments. It will be seen that in the mixed lymphocyte culture the counts in the autologous control culture are similar for each group, the difference in transformation indices being due to the varying degrees of stimulation in allogeneic culture. In the PHA cultures, there is no significant difference in mean counts between patients and control subjects in either the irradiated or the non-irradiated cultures.

\section{Discussion}

The mixed lymphocyte culture test relies on the genetic disparity between two individuals, at or related to the HL-A locus, as expressed by the HL-A phenotypes on cell surfaces acting as antigenic stimuli in the induction of blastogenesis in each other's lymphocytes. The stimulation is two-way and one cell population is therefore prevented from transforming by prior irradiation. The measurement of thymidine uptake is thus confined to the responding population's lymphocytes.

Our results obtained by use of this test appear to suggest a depression of this function in the Crohn's group as compared to the normal subject. This supports the concept of a relative state of anergy in Crohn's disease suggested by previous work. (Jones et al, 1969; Williams, 1965; Brown et al, 1970; Walker and Greaves, 1969; Bendixen, 1969).

The anergy shown in Crohn's disease has suggested a link with sarcoidosis and many analogies have been

\begin{tabular}{lll}
\hline Mixed Lymphocyte Culture Reaction & Allogeneic Culture & Autologous Culture \\
\hline Normal stimulators & $47392 \pm 9079$ & $2549 \pm 593$ \\
Normal responders & $17622 \pm 6720$ & $2141 \pm 462$ \\
Normal stimulators & $85926 \pm 18410$ & $1980 \pm 1620$ \\
Crohn's responders & & \\
Crohn's stimulators & Non-irradiated Culture & Irradiated Culture \\
PHA Reaction & $38898 \pm 9320$ & $3885 \pm 901$ \\
Normal subjects & $41208 \pm 10700$ & $4524 \pm 1220$ \\
Crohn's patients & &
\end{tabular}

Table V Mean Cpm ( \pm SEM) obtained from normal subjects and Crohn's patients on stimulation by mixed lymphocyte culture reaction and by $P H A$. 
drawn between the two conditions (Brostoff and Walker, 1971). Recent work with the leucocyte migration inhibition test (Brostoff and Walker, 1971; Willoughby and Mitchell, 1971; Richens, Gough, and Williams, 1973) has shown that a high proportion of patients with Crohn's disease show altered migration patterns when incubated with sarcoid spleen suspensions.

In contrast with the results for mixed lymphocyte culture no evidence of impaired transformation was obtained with PHA stimulation. Considerable variation was seen on repeated tests with the same subject. This may reflect the activity of inhibitory factors in plasma (Holt, Ling, Winter, McCarthy, Read, and Yoffey, 1966). It is thought that PHA stimulation may not give a true reflection of immunocompetence (Han and Sokal, 1970), and that its mitogenic effect is concerned with its leucocyte agglutinating property (Hirschhorn, Kolodny, Hashem, and Bach, 1963). Although stimulation by PHA results in lymphocyte stimulation which is morphologically similar to that seen by other types of antigenic stimuli, it appears to be different in quantitative, qualitative, and biochemical respects.

The disparity seen between stimulation in the mixed lymphocyte culture reaction and by PHA may be explained on this basis, though the results with PHA are not in agreement with earlier work (Brown et al, 1970; Walker and Greaves, 1969).

No correlation was seen between transformation indices in either test and the taking of immunosuppressive drugs, though it is reported that prednisolone inhibits lymphocytic DNA synthesis induced by PHA (Caron, 1967).

In conclusion, the data for mixed lymphocyte culture provide additional support for the concept of a degree of anergy in Croyn's disease. It is suggested that the failure to confirm this finding in the PHA experiments is due to the mode of action of this non-specific mitogen.

We are grateful for the advice of Dr S. Nelson and for the help of Mr C. Darke in carrying out the HL-A phenotyping.

\section{References}

Bendixen, G. (1969). Cellular hypersensitivity to components of intestinal mucosa in ulcerative colitis and Crohn's disease. Gut, 10, 631-636.

Brostoff, J., and Walker, J. G. (1971). Leucocyte migration inhibition with Kveim antigen in Crohn's disease. Clin. exp. Immunol., 9, 707-711.

Brown, S. M., Taub, R. N., Present, D. H., and Janowitz, H. D. (1970). Short-term lymphocyte cultures in regional enteritis. Lancet, $1,1112$.

Caron, G. A. (1967). Prednisolone inhibition of DNA synthesis by human lymphocytes induced in vitro by phytohaem agglutinin. Int. Arch. Allergy, 32, 191-200.

Han, T., and Sokal, J. E. (1970). Lymphocyte response to phytohaemogglutinin in Hodgkin's disease. Amer. J. Med., 48, 728-734.

Hirschhorn, K., Kolodny, R. L., Hashem, N., and Bach, F. (1963). Mitogenic action of PHA. (Letter). Lancet, 2, 305-306.

Holt, P. J. IL., Ling, N. R., Winter, G. C. B., McCarthy, C. F., Read, A. E., and Yoffey, J. M. (1966).

Holt, P. J. L., Ling, N. R., Winter, G. C. B., McCarthy, C. F., Read, A. E., and Yoffey, J. M. (1966). Response to phytohaemagglutinin. Lancet, 1, 980-981.

Jones, J. V., Housley, J., Ashurst, P. M., and Hawkins, C. F. (1969). Development of delayed hypersensitivity to dinitrochlorobenzene in patients with Crohn's disease. Gut, 10, 52-66.

Richens, E. R., Gough, K. R., and Williams, M. J. (1973). Leucocyte migration studies with spleen preparations in Crohn's disease. Gut, 14, 376-379.

Walker, J. G., and Greaves, M. F. (1969). Df,layed hypersensitivity and lymphocyte transformation in Crohn's disease and proctocolitis. Gut, 10, 414.

Williams, W. J. (1965). A study of Crohn's syndrome using tissue extracts in the Kveim and Mantoux tests. Gut, 6, 503-505.

Willoughby, J. M. T, and Mitchell, D. N. (1971). In-vitro inhibition of leucocyte migration in Crohn's disease by a sarcoid spleen suspension. Brit. med. J., 2, 155-157. 